\title{
Improved image processing of road pavement defect by infrared thermography
}

\author{
Jun-Gi Sim \\ Ph.D., Structural Engineering Research Division, Korea Bridge Institute Co.,Ltd., Korea \\ e-mail:sjk0605@korea.ac.kr
}

\begin{abstract}
This paper intends to achieve improved image processing for the clear identification of defects in damaged road pavement structure using infrared thermography non-destructive testing (NDT). To that goal, 4 types of pavement specimen including internal defects were fabricated to exploit the results obtained by heating the specimens by natural light. The results showed that defects located down to a depth of $3 \mathrm{~cm}$ could be detected by infrared thermography NDT using the improved image processing method.
\end{abstract}

Key words: infrared thermography, heat source from natural light, image processing, defect, asphalt

\section{Introduction}

The origin of the method using infrared thermal camera dates back to 1800s when William Herschel in UK discovered the infrared spectrum and was completed later based upon the achievements of several researchers [5]. The recent advances realized in the manufacture of infrared camera equipment dropped down its price and opened new potential applications in diversified sectors. The infrared camera provides a contactless tool enabling to detect visually any anomaly in various materials using the difference in the surface temperature distribution of the material. Owing to such feature, the methods using the infrared camera are expected to widen their applications extensively in the future.

Moropoulou et al. (2011) inspected the superficial defect in an airport runway by thermography using the Avio Tvs 2000 Mk II LW equipment. Since superficial defect in the airport runway may cause accidents, quality survey must imperatively be done on the pavement to prevent them [6]. Thermography was proposed as a cost-effective method for such survey $[2,6]$. The mooring on which thermography was applied used broken stones as pavement material and was one of the oldest part of the airport. The asphalt-paved Bravo mooring and the runway repaved by asphalt with a thickness of about $30 \mathrm{~mm}$ were also surveyed. From the survey results, it appeared that, compared to previous methods using destructive testing to detect defect, thermography enabled to inspect rapidly surfaces with wide area like asphalted roads or airport runways. Besides, non-destructive testing (NDT) by thermography presented difficulties in detecting exactly the depth or thickness of the defect zone according to the conditions on the testing site, and due to the change in the emissivity 
with respect to the thickness of the clouds or the surface humidity, the radiation of solar heat and the material properties of the surface. Accordingly, it was necessary to combine thermography with a NDT method enabling to diagnose accurately the defect or to use additional data related to the defect [6].

Sim et al. $(2008,2009)$ proposed the application of a black coating on the surface of the specimen to minimize the effect of the superficial emissivity during the application of thermography combined together with an image processing algorithm using the Gauss filter and the Prewitt mask for the damaged zone of the defect [7,8]. Recently, Kim et al. (2014) developed a calibration target for infrared thermal imaging camera using finite element heat transfer analysis in the domain of visual inspection technology so as to increase the accuracy of the geometrical data of the image [3]. Other researchers also exploited image processing to measure the area in specimens made of composite materials [10]. Lately, Sim et al. (2015) improved the previous thermography by using the natural light as heat source for the road pavement [9]. These authors combined the analysis of the dimensional temperature distribution and the image processing. The results showed that the dimensionless temperature graph enabled to detect at least defects with rectangular dimensions of $20 \times 20 \mathrm{~mm}$ up to depth of $30 \mathrm{~mm}$ but that the visual image processing result could detect only defects with rectangular dimensions of $60 \times 60 \mathrm{~mm}$ up to depth of $10 \mathrm{~mm}$ for simultaneous heating.

Accordingly, this study intends to improve the image processing method developed in the previous research for the detection of defect in road pavement using thermography so as to detect minimal defect to the extent realized by the dimensionless temperature graph.

\section{Application of Thermography}

\subsection{Dimensionless Temperature Graph}

The heat source in thermography is the solar heat in its natural state. The solar heat is very sensitive to the amount of radiated infrared rays according to external environmental conditions [1]. The propagation of the thermal energy used in thermography can be formulated by the governing equation of heat transfer in Eq. (1). The thermal diffusivity $\alpha$ can be expressed by $k / \rho C$ where $k$ is the thermal conductivity, $\rho$ is the density and, $C$ is the specific heat of the material. The thermal conductivity, which is proportional to the thermal diffusivity, is a major indicator discriminating the superficial temperature at the defect present in the material and the superficial temperature at the zones without defect. The thermal conductivity $k$ can be expressed by $W /(m \cdot K)$ where $W$ is the quantity of heat, $m$ is the sample thickness and, $\mathrm{K}$ is the temperature difference. The value of $k$ for the asphalt road pavement in concern in this study is $0.33 \mathrm{~W} /(\mathrm{m} \cdot \mathrm{K})$ at room temperature $\left(20^{\circ} \mathrm{C}\right)$ and the value of $k$ for the wooden material used as internal defect in this study runs between 0.14 and $0.19 \mathrm{~W} /(\mathrm{m} \cdot \mathrm{K})$ at room temperature $\left(20^{\circ} \mathrm{C}\right)$. The difference between these values of $k$ provides an indicator enabling to distinguish the defect. Larger difference appears in the temperature distribution as much as the difference in $k$ is large. Other data on the depth or size of the defect can be obtained through post-processing [4]. However, this difference in the temperature distribution is influenced by the external environment [5]. 
$\alpha \nabla^{2} T=\frac{\delta T}{\delta t}$

where $\alpha=$ thermal diffusivity; $T=$ absolute temperature; and, $t=$ time.

The eventual presence of defect is detected by the difference in the superficial temperature. This temperature difference for the detection of defect is calculated by Eq. (2) proposed by Meola and Carlomagno (2006) [5].

$\bar{T}=\frac{\left|T_{s}-T_{d}\right|}{\left|T_{s}-T_{r}\right|}$

where $T_{r}=$ temperature of specimen before heating; $T_{d}=$ temperature at defect location; $T_{S}=$ temperature at surrounding of defect; and, $\bar{T}=$ relative temperature change.

Eq. (2) is expressed as the ratio of the absolute temperature differences between the healthy part and the damage part. The relative characteristics of the temperature difference are not considered. Sim et al. (2008) suggested Eq. (3) for the detection of internal defect in concrete that minimizes the influence of the external environment by a new thermographic method using the relative temperature enabling to assess definite temperature change even under change in the surrounding temperature [8]. In order to evaluate the eventual improvement of the damage detection by the improved image processing technique during the application of thermography, the dimensionless temperature graph is used since the graph can detect minimal defect.

$\Delta T=\frac{T_{s}-T_{d}}{T_{s}}$

Accordingly, Eq. (3) is used in the analysis of the superficial temperature for the detection of internal defect in the road pavement so as to minimize the problems encountered when using the natural light as heat source. Moreover, Sim et al. (2009) calibrated graphically the error occurring in irregular surface using the improved image processing technique [7].

In the present study, the infrared camera (model TH7800N of NEC) adopted for the thermography test provides high temperature sensitivity up to $0.1^{\circ} \mathrm{C}$ at room temperature of $30^{\circ} \mathrm{C}$ and a resolution of $320 \times 240$ pixels enabling to analyze the image at the pixel level. Table 1 arranges the specifications of the infrared camera.

Natural light is adopted as heat source in the defect detection of road pavement by thermography. Thermographic imaging is done every 10 minutes from 10:40am to 2:30pm on the asphalt specimens from a vertical distance of $30 \mathrm{~cm}$ to detect efficiently the internal defect in the road pavement.

Table 1: Specifications of infrared camera [9]

\begin{tabular}{|c|c|c|c|}
\hline $\begin{array}{c}\text { Field of view } \\
(\mathrm{mrad})\end{array}$ & Temperature sensitivity $\left({ }^{\circ} \mathrm{C}\right)$ & Spectral range $(\mu \mathrm{m})$ & Image frequency $(\mathrm{Hz})$ \\
\hline 1.5 & $0.1\left(\right.$ at $\left.30^{\circ} \mathrm{C}\right)$ & $8-14$ & 60 \\
\hline
\end{tabular}




\subsection{Application of Image Processing Technique}

Smoothing is done on the inter-pixel image change obtained by Gauss filtering through the introduction of the weighting factor expressed in Eq. (4). For the image modified by such weighting factor, the difference is calculated by the process expressed in Eqs. (5) and (6). Here, Eq. (4) is the weighting factor of the $5 \times 5$ mask in the Gauss filtering and $\sigma$ is the input phase that is the standard deviation. Eqs. (5) and (6) are the images calculated at the coordinates corresponding to the $X, Y$ masks of the Prewitt mask, respectively. The magnitude of the gradient obtained by differentiation is finally approximated by the sum of the absolute values of each component as expressed in Eq. (7). The Prewitt mask is an edge detection algorithm, which separates the image into the $3 \times 3$ mask shown in Fig. 1(c), stores the value obtained by adding the products of the masks of Figs. 1(a) and (b) with the pixel of the image, and detect the edge corresponding to the central pixel of the so-calculated image. Fig. 2 presents the flowchart of the image processing procedure.

$$
\begin{aligned}
& W(x, y)= \frac{1}{\sqrt{2 \pi \sigma^{2}}} \exp \left(\frac{-\left(x^{2}+y^{2}\right)}{2 \sigma^{2}}\right) \\
& G_{x}(x, y)=(f(x-1, y+1)+f(x, y+1)+f(x+1, y+1)) \\
& \quad-(f(x-1, y-1)+f(x, y+1)+f(x+1, y-1)) \\
& G_{y}(x, y)=(f(x+1, y-1)+f(x+1, y)+f(x+1, y+1)) \\
& \quad-(f(x-1, y-1)+f(x-1, y)+f(x-1, y+1)) \\
& E_{m}(x, y)=\sqrt{\left(G_{x}(x, y)\right)^{2}+\left(G_{y}(x, y)\right)^{2}} \rightarrow\left|G_{x}(x, y)\right|+\left|G_{y}(x, y)\right|
\end{aligned}
$$

\begin{tabular}{|l|l|l|}
\hline-1 & 0 & 1 \\
\hline-1 & 0 & 1 \\
\hline-1 & 0 & 1 \\
\hline
\end{tabular}

(a)

\begin{tabular}{|c|c|c|}
\hline-1 & -1 & -1 \\
\hline 0 & 0 & 0 \\
\hline 1 & 1 & 1 \\
\hline
\end{tabular}

(b)

\begin{tabular}{|l|l|l|}
\hline$(x-1, y-1)$ & $(x-1, y)$ & $(x-1, y+1)$ \\
\hline$(x, y+1)$ & $(x, y)$ & $(x, y+1)$ \\
\hline$(x+1, y-1)$ & $(x+1, y)$ & $(x+1, y+1)$ \\
\hline
\end{tabular}

(c)

Figure 1: Prewitt mask: (a) X-axis, (b) Y-axis mask, (c) Pixel calculation of $3 \times 3$ mask [7] 


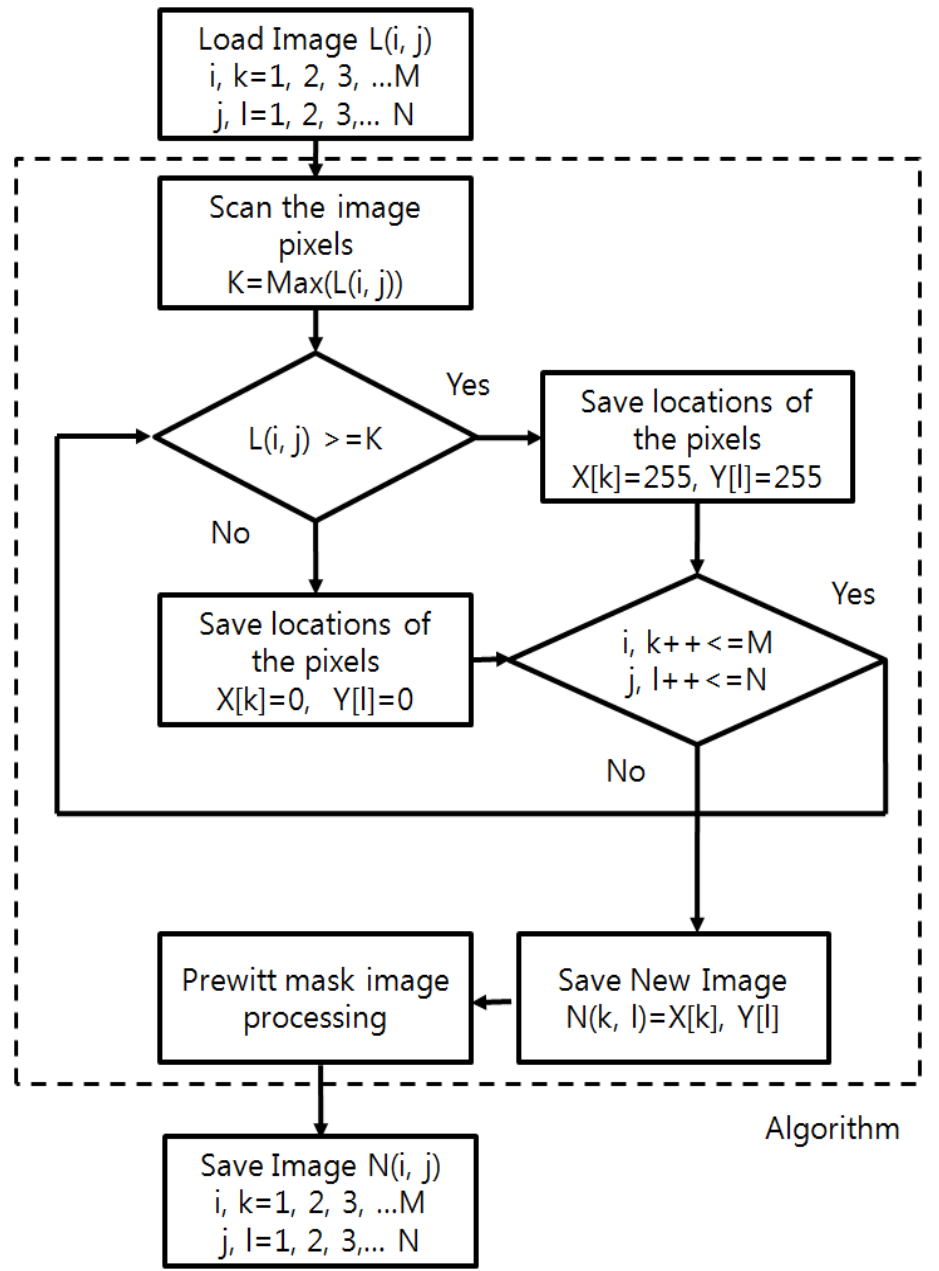

Figure 2: Image processing procedure [7]

Sim et al. (2015) attempted to detect the edge of the defective zone in the road pavement using such image processing technique but the defect detection performance appeared to be significantly lower than the dimensionless temperature graph [9]. Accordingly, the present study intends to verify the possibility to detect the defect edge by applying values of 0.15 and 0.20 instead of 0.35 for the standard deviation of the Gauss filtering in this image processing technique.

\subsection{Types of Defect in Road Pavement}

As shown in Fig. 3, the specimens for the detection of internal defect were fabricated using $200 \times 200 \mathrm{~mm}$ frames in which square wooden blocks of 20,40,60 and $80 \mathrm{~mm}$ are disposed at depths of 10, 20 and $30 \mathrm{~mm}$ from the surface to simulate the defect. Fig. 4 depicts the frame made of wood. Fig. 5 shows the completed specimens after the placing of the asphalt mixture. Fig. 6 illustrates a view of thermal imaging test using natural light. Note that the distance between the infrared camera and the specimen is approximately $2.0 \mathrm{~m}$. Table 2 gives the list and designation of the considered specimens with internal defect. 


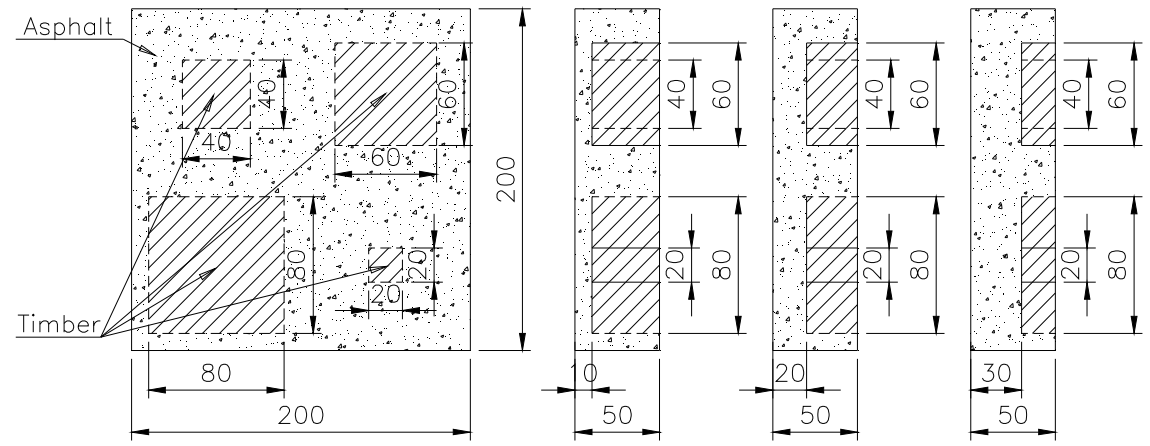

Figure 3: Details of pavement specimens with defect [9]

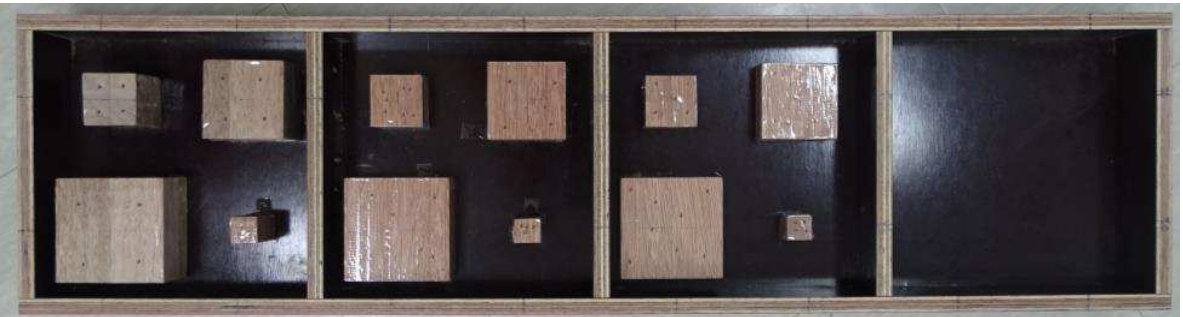

Figure 4: Frame and wooden blocks for the fabrication of pavement specimens [9]

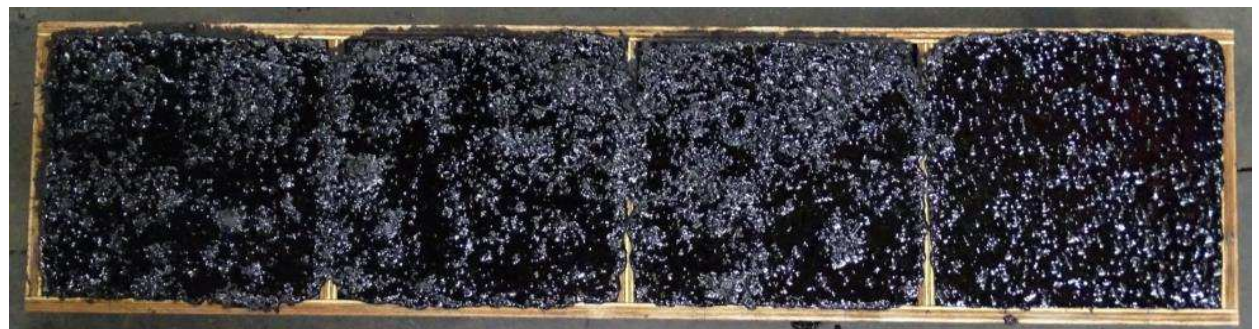

Figure 5: Completed asphalt pavement specimens [9]

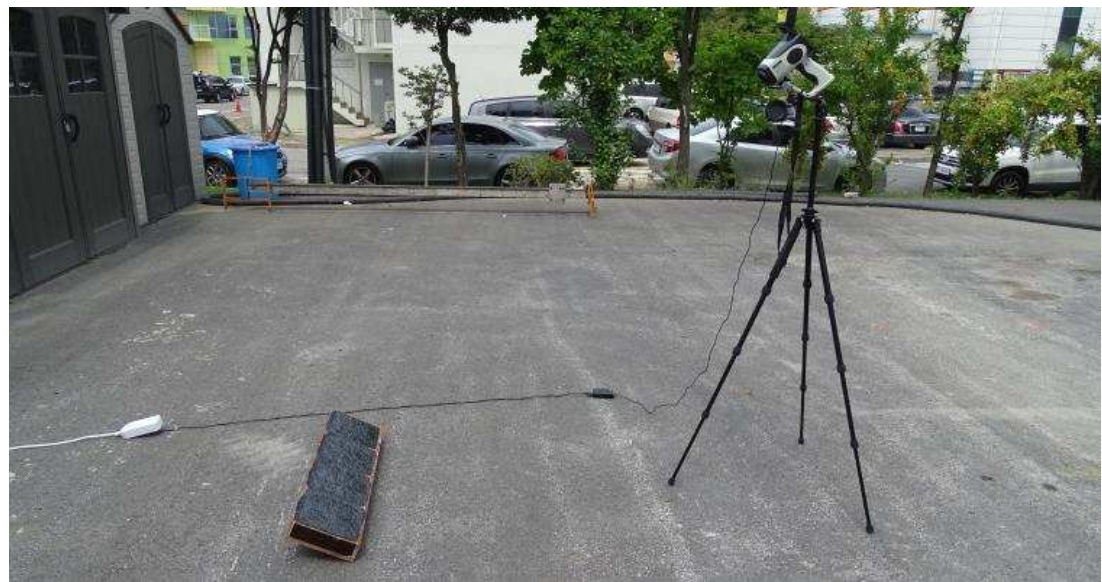

Figure 6: Thermal imaging using natural light [9] 
Table 2: Summary of pavement specimens with internal defect [9]

\begin{tabular}{|c|c|c|}
\hline $\begin{array}{c}\text { Designation of } \\
\text { specimen }\end{array}$ & Depth (mm) & $\begin{array}{c}\text { Size of the internal } \\
\text { defect }(\mathrm{mm})\end{array}$ \\
\hline S01-01-04 & 10 & $40 \times 40$ \\
\hline S02-01-06 & 10 & $60 \times 60$ \\
\hline S03-01-08 & 10 & $80 \times 80$ \\
\hline S04-01-02 & 10 & $20 \times 20$ \\
\hline S05-02-04 & 20 & $40 \times 40$ \\
\hline S06-02-06 & 20 & $60 \times 60$ \\
\hline S07-02-08 & 20 & $80 \times 80$ \\
\hline S08-02-02 & 20 & $20 \times 20$ \\
\hline S09-03-04 & 30 & $40 \times 40$ \\
\hline S10-03-06 & 30 & $60 \times 60$ \\
\hline S11-03-08 & 30 & $80 \times 80$ \\
\hline S12-03-02 & 30 & $20 \times 20$ \\
\hline S13-REF & - & - \\
\hline
\end{tabular}

In the designation $\mathrm{S} \circ \circ-\triangle \triangle-\square \square$ adopted in Table $2, \mathrm{~S}$ stands for specimen, $\circ \circ$ indicates the total number of specimens, $\triangle$ indicates the depth of the wooden block from the surface of the specimen, and $\square \square$ indicates the size of the square wooden block.

Guss asphalt mixture is used for the fabrication of the specimens as road pavement material usually adopted for paving bridge deck owing to its remarkable water-tightness and compliance to deformation. This material is applied in this study due to its properties which render compaction needless and the possibility to mold the specimens without voids by pouring it in the frame.

Aggregate with the size listed in Table 3 is adopted and normal AP-5 asphalt binder for road pavement is admixed with a weight ratio of $9.3 \%$ so as to fabricate the specimens by heating the compound at temperature higher than $220^{\circ} \mathrm{C}$.

Table 3: Asphalt specifications [9]

\begin{tabular}{|c|c|}
\hline Aggregate type & Weight ratio (\%) \\
\hline 13 mm aggregate & 35 \\
\hline Fine aggregate & 34.5 \\
\hline Filler & 30.5 \\
\hline
\end{tabular}

\section{Comparison of Results by Dimensionless Temperature Graph and Improved Image Processing}

\subsection{Dimensionless Temperature Graph of Wooden Defect in Road Pavement}

The use of the difference in the distribution of the superficial temperature using the natural light alone is insufficient to distinguish the relative temperature difference since higher superficial temperature can be measured for larger defective zone in morning time whereas 
lower superficial temperature can be measured for larger defective zone in the afternoon. Accordingly, the influence of the external environment is minimized by adopting the method using the relative temperature proposed in the previous chapter.

As shown in Fig. 7, when the defect size is $80 \times 80 \mathrm{~mm}$ and taking time zero at 10:40am, the dimensionless temperature graph exhibits large difference and enables to distinguish any defect up to a depth of $30 \mathrm{~mm}$. For the defect size of $60 \times 60 \mathrm{~mm}$ in Fig. 8, large difference is observed in the dimensionless temperature graph even at 200 min corresponding to 2:00pm and makes it possible to detect all the defects. Moreover, the difference in the dimensionless temperature graph in Fig. 9 for the defect size of $40 \times 40 \mathrm{~mm}$ enables to distinguish all the defects at $230 \mathrm{~min}$ that is $2: 30 \mathrm{pm}$. Finally, the dimensionless temperature graphs of Fig. 10 for the defect size of $20 \times 20 \mathrm{~mm}$ also indicate all the defects at $140 \mathrm{~min}$ corresponding to 1:00pm. This series of observation verify that the dimensionless temperature graph can detect any defect up to $20 \times 20 \mathrm{~mm}$ at depth of $30 \mathrm{~mm}$ using the change in the solar radiation being in morning or in afternoon.

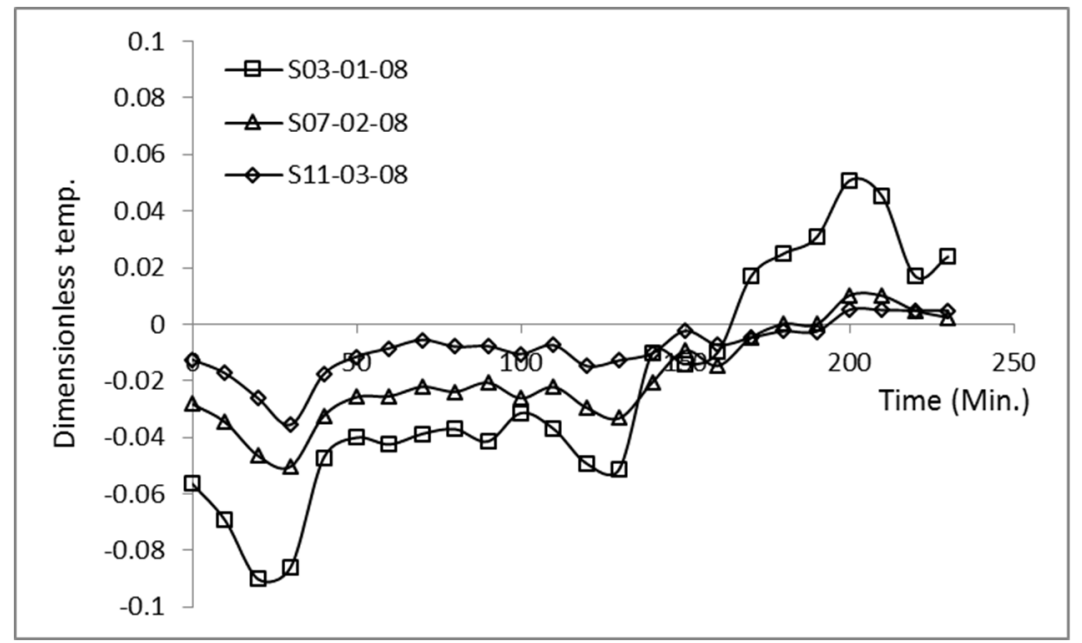

Figure 7: Surface temperature distribution at defect with size of $80 \times 80 \mathrm{~mm}$ [9]

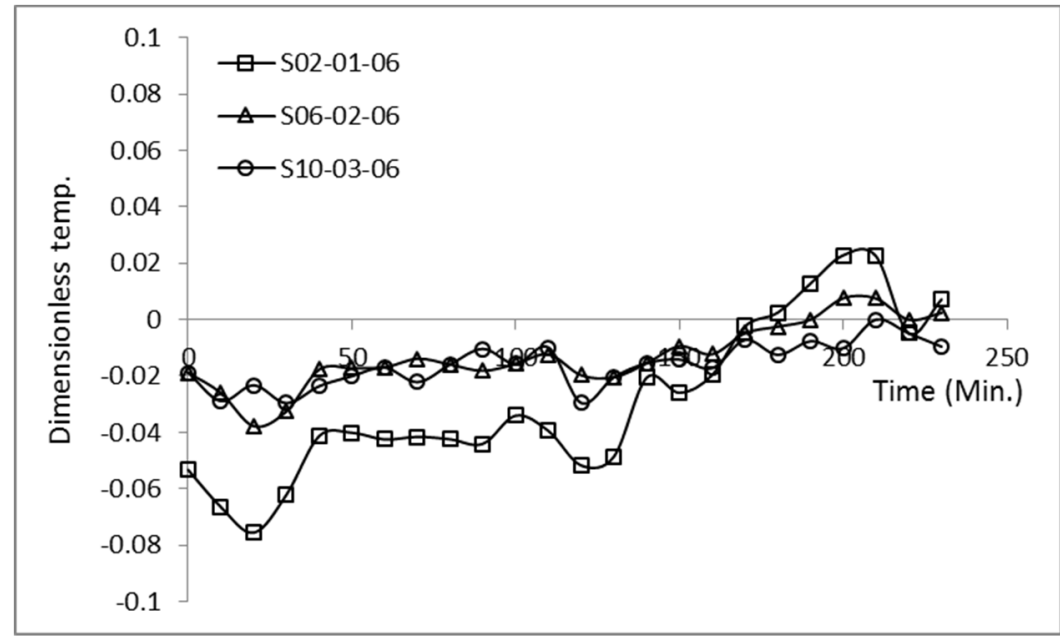

Figure 8: Surface temperature distribution at defect with size of $60 \times 60 \mathrm{~mm}$ [9] 


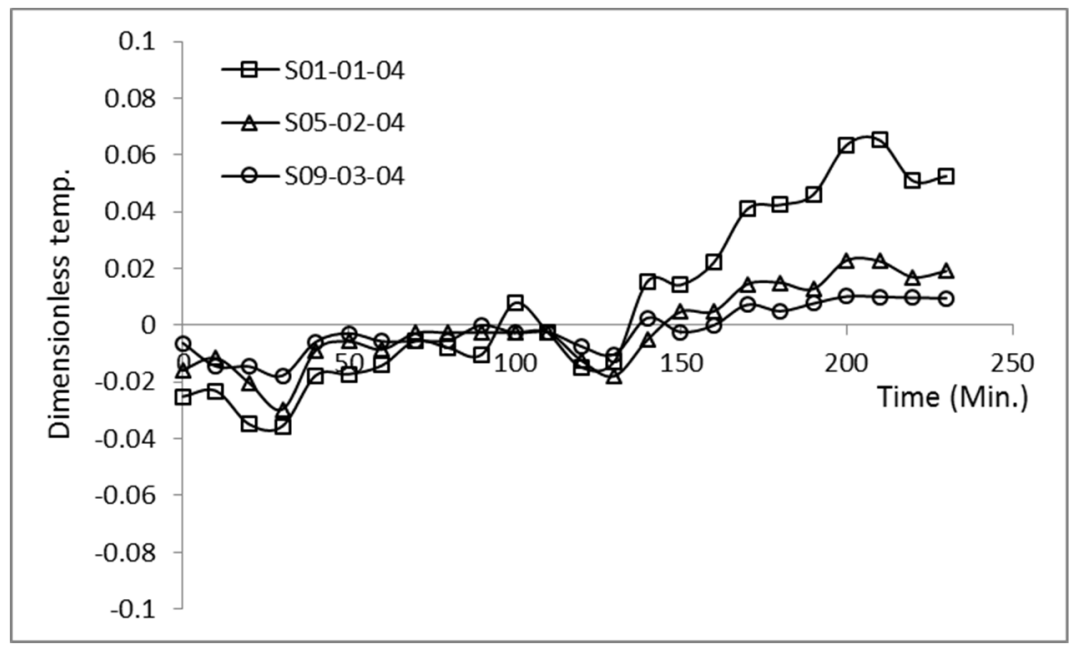

Figure 9: Surface temperature distribution at defect with size of $40 \times 40 \mathrm{~mm}$ [9]

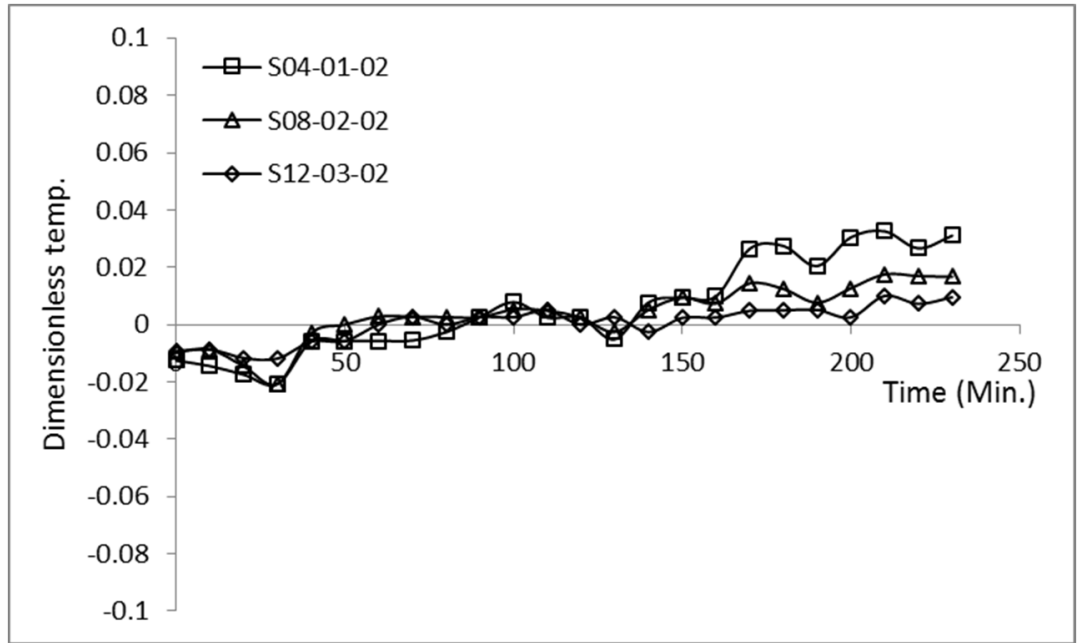

Figure 10: Surface temperature distribution at defect with size of $20 \times 20 \mathrm{~mm}$ [9]

\subsection{Comparison with Improved Image Processing}

In parallel to the detection of defect using the surface temperature, image masking using the Prewitt operator is used to calibrate graphically the flaws occurring in irregular surface in order to detect invisible internal defects by thermography.

Fig. 11 shows the original thermal image captured at 10:40am on the specimen with defect at depth of $10 \mathrm{~mm}$ together with the images processed by Prewitt mask. Previously, defect detection could be done only up to S02-01-06 but it appears that detection of the defect can now be done up to S01-01-04 when applying a standard deviation of 0.15 in the Gauss filtering before Prewitt masking. 


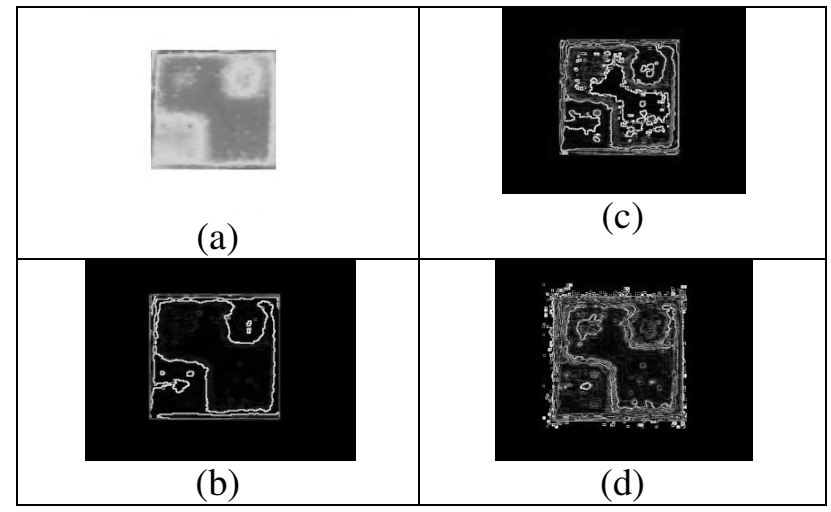

Figure 11: Result of Prewitt mask: (a) original image; (b) image processed with $\sigma=0.35$; (c) image processed with $\sigma=0.20$; (d) image processed with $\sigma=0.15$ (defect at depth of $10 \mathrm{~mm}$, 10:40am)

Fig. 12 relates the thermography of the specimen with defect at depth of $20 \mathrm{~mm}$ captured at $12: 50 \mathrm{pm}$. The previous image processing failed in identifying clearly the edge of the defect but it can be seen that, when a standard deviation of 0.15 is applied in the Gauss filtering, the image processing is improved to an extent enabling to distinguish the defect up to S06-02-06.

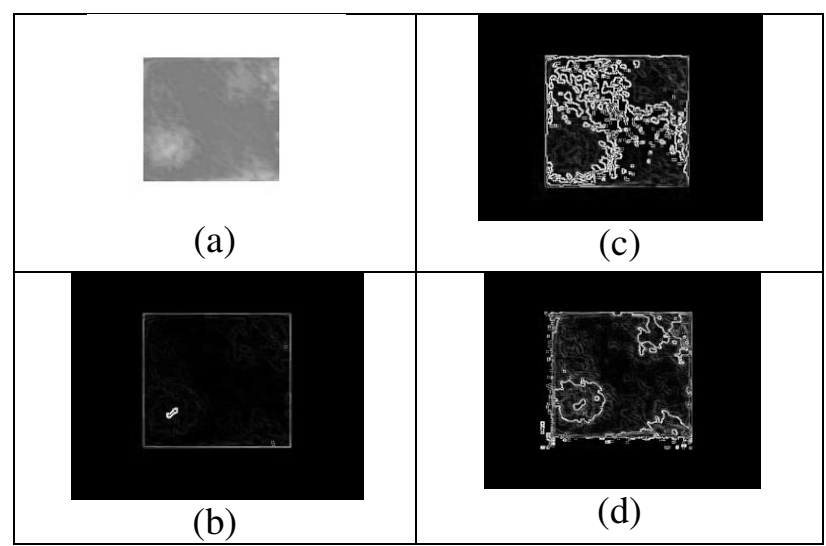

Figure 12: Result of Prewitt mask: (a) original image; (b) image processed with $\sigma=0.35$; (c) image processed with $\sigma=0.20$; (d) image processed with $\sigma=0.15$ (defect at depth of $20 \mathrm{~mm}$, $12: 50 \mathrm{pm})$

Fig. 13 arranges the images captured at 12:50pm for the specimen with defect at depth of 30 $\mathrm{mm}$. Here also, the application of a standard deviation of 0.15 in the Gauss filtering appears to identify the defect edge of S11-03-08 that could be merely distinguished previously. 


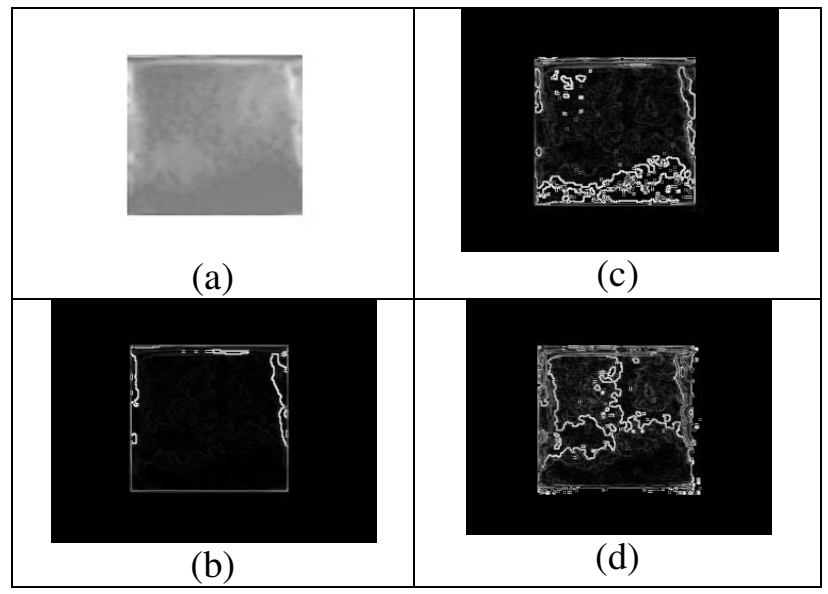

Figure 13: Result of Prewitt mask: (a) original image; (b) image processed with $\sigma=0.35$; (c) image processed with $\sigma=0.20$; (d) image processed with $\sigma=0.15$ (defect at depth of $30 \mathrm{~mm}$, $13: 30 \mathrm{pm})$

\section{Conclusion}

The results obtained by thermography using an improved image processing technique for the detection of wooden defects located deeply in the road pavement can be summarized as follows: The detection of wood blocks inside the asphalt pavement using the relative surface temperature analysis in thermography exploiting the natural light as heat source enabled to distinguish defect with size of $20 \times 20 \mathrm{~mm}$ at depth of $30 \mathrm{~mm}$.

Previous method could distinguish defect with size up to $60 \times 60 \mathrm{~mm}$ in the specimens with defect depth of $10 \mathrm{~mm}$ but the improvement appeared to allow the detection of smaller defect with size of $40 \times 40 \mathrm{~mm}$. Moreover, the identification of the edge of the defect in the specimens with defect depths of 20 and $30 \mathrm{~mm}$ that was practically impossible by the previous method has become possible for defect with size of $60 \times 60 \mathrm{~mm}$ after the improvement.

\begin{tabular}{|c|c|c|c|c|c|c|c|c|}
\hline \multirow{2}{*}{$\begin{array}{c}\text { Defect } \\
\text { depth } \\
(\mathrm{mm})\end{array}$} & \multicolumn{4}{|c|}{ Previous method (mm) } & \multicolumn{4}{c|}{ Improved method (mm) } \\
\cline { 2 - 9 } & 40 & 60 & 80 & 20 & 40 & 60 & 80 & 20 \\
\hline 10 & $\times$ & $\mathrm{o}$ & $\mathrm{o}$ & $\times$ & $\mathrm{o}$ & $\mathrm{o}$ & $\mathrm{o}$ & $\times$ \\
\hline 20 & $\times$ & $\times$ & $\times$ & $\times$ & $\times$ & $\mathrm{o}$ & $\mathrm{o}$ & $\times$ \\
\hline 30 & $\times$ & $\times$ & $\times$ & $\times$ & $\times$ & $\mathrm{o}$ & $\mathrm{o}$ & $\times$ \\
\hline
\end{tabular}

In case where the natural light sensitive to the external environment is used as heat source in thermography, the proposed image processing technique appears to enable the detection of internal defects in asphalt with smaller size and larger depth than the previous method.

\section{Acknowledgements}

This research was supported by grants from Korea Bridge Institute Co., Ltd., Korea Institute of Civil Engineering and Building Technology (KICT) and Constructional Research \& Development Program (16SCIP-C079146-03), "Development of Korea Performance-Based Evaluation Techniques of 
Performance-Centered Management and Operation for SOC Structures" funded by Ministry of Land, Infrastructure and Transport (MOLIT) of Korea government and Korea Agency for Infrastructure Technology Advancement (KAIA).

\section{References}

[1] Bennett, C.A., Jr. and Patty, R. R.(1982) "Thermal wave interferometry: a potential application of the photoacoustic effect." Journal of Applied Optics, Vol. 21, No. 11, pp.49-54, DOI: 10.1364/AO.21.000049.

[2] Jeff, R. Brown and Hamilton III (2003) "NDE of Reinforced Concrete Strengthened with FiberReinforced Polymer Composite using Infrared Thermography." InfraMation the thermographer's conference 2003

[3] Kim, S., Choi, M., Park, J., Shin, K. and Lee, E. (2014) "Development of Calibration Target for Infrared Thermal Imaging Camera." Journal of the Korean Soc. for nondestructive testing, Vol. 34, No. 3, pp.248-253. (in Korean)

[4] Lugin, S. and Netzelmann, U. (2005) "An effective compression algorithm for pulsed thermography data." NDT \& E Int., Vol. 38, No. 6, pp.485-490, DOI: 10.1016/j.ndteint. 2005.01.005.

[5] Meola, C. and Carlomagno, G.M. (2006) "Application of infrared thermography to adhesion science." Journal of Adhesion science and Technol., Vol. 20, No. 7, pp.589-632, DOI:10.1163/156856106777412491.

[6] Moropoulou, A., Avdelidis, N.P., Koui, M. and Kakaras, K. (2001) "An application of thermography for detection of delaminations in airport pavements." NDT \& E Int., Vol. 34, No. 5, pp.329-335, DOI:10.1016/S0963-8695(00)00047-5.

[7] Sim, J., Moon, D., Chung, L., Lee, J., and Zi, G. (2009) "The Efficiency of External Heat Sources for Infrared Thermography Applied Concrete Structures and the Improvement of the Defect-identification." Journal of the Korea Institute for Structural Maintenance Inspection, Vol. 13, No. 5, pp.169-179 (in Korean).

[8] Sim, J., Zi, G., Park, J., Cho, H., and Lee, J. (2008) "Review of the Current infrared Thermorgraphy Techniques for Detecting Defects in Civil Structures." Journal of the Korea Institute for Structural Maintenance Inspection, Vol. 12, No. 3, pp.71-83 (in Korean).

[9] Sim, J., Kim, K. (2015) "Detecting of the defects of pavement of a road by using infrared thermography." Journal of the Korea Society Advanced Composite Structures, Vol. 6, No. 3, pp.69-76 (in Korean), DOI: http://dx.doi.org/10.11004/kosacs.2015.6.3.069.

[10] Son, B.J. and Lee, K.H. (2015) "The Area Measurement of Composite Specimen using Digital Image Processing." Journal of the Korea Society Advanced Composite Structures, Vol. 6, No. 2, pp.17-22 (in Korean), DOI :10.11004/kosacs.2015.6.2.017. 